\title{
Contravozes: frestas de um processo criativo de desenho de paisagens urbanas distópicas
}

Contravoces: grietas en un proceso creativo de dibujar paisajes urbanos distópicos

Countervoices: cracks of a creative process of drawing dystopic cityscapes

Rafael Ghiraldelli da Silva

IA/Unicamp, Campinas, Brasil.ghiralds@gmail.com 


\title{
Resumo
}

Discorre-se aqui acerca do processo criativo de desenhos feitos para a sequência de abertura em animação 2D de um curta-metragem em desenvolvimento, dirigido pelo autor deste ensaio. Intitulado Contravozes, o referido projeto visa representar uma versão distópica da cidade de Campinas, SP, com base nas formas de ocupação pública de outrora de seus lugares de passagem mais conhecidos atualmente.

Palavras-Chave: Distopia. Fabulação. Contravozes. Filme. Desenho.

\section{Resumen}

Discutimos el proceso creativo de los dibujos realizados para la secuencia de apertura en animación 2D de un cortometraje en desarrollo, dirigido por el autor de este ensayo. Titulado Contravoces, el proyecto mencionado tiene como objetivo representar una versión distópica de la ciudad de Campinas basada en las formas pasadas de ocupación pública de sus lugares de paso más conocidos hoy en día.

Palavras-Clave: Distopía. Fabulación. Contravoces. Pelicula. Dibujo.

\begin{abstract}
Here we discuss the creative process of drawings made for a 2D animation opening sequence of a short film under development, directed by the author of this essay. Entitled Countervoices, the aforementioned project aims to represent a dystopian version of the city of Campinas - SP based on the forms of public occupation that used to be the most known places of passage today.
\end{abstract}

Keywords: Dystopia. Fabulation. Countervoices. Movie. Drawing. 


\section{INTRODUÇÃO}

"As I've said many times, the future is already here. It's just not very evenly distributed."

(GIBSON, 2018)

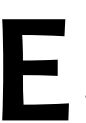
ste ensaio ${ }^{1}$ começa com uma sucinta explanação dos conceitos de distopia e de fabulação para, em seguida, apresentar trabalhos realizados pelo artista sulafricano William Kentridge (1955 - ) e pelo cineasta brasileiro Adirley Queirós (1970 - ) - que incluiu desenhos feitos pelo ator Cláudio Irineu Shokito em seu longametragem de 2014, Branco Sai, Preto Fica.

Os desenhos de Kentridge e de Shokito dialogam de formas distintas com a ideia de distopia enquanto "mau lugar", e são referências-chave para a realização de estudos para um projeto de curta-metragem em desenvolvimento, dirigido pelo autor deste texto. Intitulado Contravozes, o filme contará com sequências em animação 2D que deverão introduzir o espectador a uma versão distópica da cidade de Campinas, SP,

\footnotetext{
${ }^{1}$ Relata-se aqui parte da pesquisa de mestrado em andamento (2018-2021) realizada pelo autor na linha de Poéticas Visuais e Processos Criativos em Artes Visuais do Instituto de Artes da Universidade Estadual de Campinas (IA/Unicamp), sob orientação da Prof.a Dr. a Sylvia Furegatti, com o apoio da Coordenação de Aperfeiçoamento de Pessoal de Nível Superior (CAPES).
} 
por meio de desenhos que ressignificam os elementos mais reconhecidos de sua paisagem urbana contemporânea.

\title{
FABULAÇÃO COMO ELEMENTO MOBILIZADOR DE IMAGINÁRIOS DISTÓPICOS
}

O processo criativo aqui relatado teve início com uma investigação sobre quando o termo "distopia" (do grego dýs-, mal; dificuldade + tópos, lugar) foi utilizado pela primeira vez. Isso se deu em 1868, em um discurso feito pelo filósofo e economista britânico John Stuart Mill (1806-1873) no âmbito particular das controvérsias sobre o direito de propriedade da terra na Irlanda - que ainda fazia parte do Reino Unido na época. Ali, o referido conceito surgiu como um antônimo, isto é, uma derivação tardia do conceito de utopia, que, por sua vez, ao longo dos séculos 19 e 20, também se afirmaria como um conceito empregado em acepções bastante diversas do sentido irônico de (não) localidade conferido inicialmente por Thomas More (14781535) à sua nação fictícia ideal ${ }^{2}$.

\begin{abstract}
Posso me permitir, como alguém que, ao lado de muitos outros melhores que eu, tem sido acusado de Utópico, congratular o Governo por se ter juntado a essa boa companhia. É talvez demasiado elogioso chamá-los Utópicos; deveriam antes ser chamados dis-tópicos ou cacotópicos. O que é comumente chamado Utópico é algo demasiado bom para ser praticável; mas o que eles parecem favorecer é demasiado mau para ser praticável. (MILL, 1988, p. 248)
\end{abstract}

Desde então, o dualismo utopia-distopia - "bom lugar" versus "mau lugar" - serviu de inspiração incontornável para uma série de narrativas do campo da ficção especulativa. Diferentes futuros foram traçados por autores de tendências ideológicas diversas para descrever os rumos que a humanidade tomaria com base

\footnotetext{
2 Conforme apresentado em sua obra mais conhecida: o livro Utopia. Vide More (2018).

3 Tradução do autor do texto original em inglês: "I may be permitted, as one who, in common with many of my betters, have been subjected to the charge of being Utopian, to congratulate the Government on having joined that goodly company. It is, perhaps, too complimentary to call them Utopians, they ought rather to be called dys-topians, or cacotopians. What is commonly called Utopian is something too good to be practicable; but what they appear to favour is too bad to be practicable."
} 
nos acontecimentos do âmbito sócio-político e tecnológico de suas respectivas épocas. Tanto que, ao pensar somente nos filmes de longa-metragem que abordam essa temática, uma série de exemplos emblemáticos já vem à mente, tendo há muito se consolidado como pontos de referência definitivos da chamada cultura pop ocidental. É o caso de Blade Runner: O Caçador de Androides (1982, dir. Ridley Scott), a cinessérie Matrix (1999-2003, dir. Lilly e Lana Wachowski), Minority Report: A Nova Lei (2002, dir. Steven Spielberg), V de Vingança (2005, dir. James McTeigue), entre muitos outros.

As diferentes distopias representadas por esses filmes são desenvolvidas a partir da chave da fabulação. Pode parecer estranho para alguns relacionar a ideia de distopia enquanto "mau lugar" com a de fábula enquanto gênero literário próprio de pequenas narrativas "em prosa ou em verso em que se aproveita a ficção alegórica para sugerir uma verdade ou reflexão de ordem moral, com intervenção de pessoas, animais e até entidades inanimadas" (FÁBULA, 2015, s.p.). No entanto, o que vem a ser ressaltado de fato no contexto deste ensaio é um significado outro. Quando se fala em fabulação aqui, refere-se mais à noção deleuziana do fabular (DELEUZE, 1985; 2007) que se dá em estado de devir e que compreende, grosso modo, uma forma de criação, de pensamento que faz crer em um novo real. Em outras palavras, o ser que fabula é aquele que

[...] foi afetado por algo, maior que ele mesmo, algo ao qual ele não pode responder com seus recursos habituais, algo que foge de seus movimentos ordinários. Pode-se dizer que o indivíduo se deparou com um problema que o levou a fabular. Ou que criou para ele um campo fértil à fabulação. (ZACHARIAS; ZEPPINI, 2018, p. 281)

Portanto, fabular implica, mas não exige, encarar um determinado problema concreto e cunhar uma realidade em potencial, decorrente dos desdobramentos imaginados para o referido problema. Se, no caso das utopias, as soluções buscadas se dão a partir de projeções otimistas para o tempo por vir, predomina nas distopias o pessimismo - o worst-case scenario. Ou seja, abrem-se "espaços de ficção" (DE CERTEAU, 1998): frestas que reinventam o cotidiano a partir de referências a lugares conhecidos do mundo real. Não se trata de restringir a imaginação a uma 
compreensão sobre como tais lugares seriam ou em que medida continuariam existindo se determinado evento catastrófico ocorresse, mas sim de uma atitude criativa que propõe um mapeamento de resistências possíveis a projetos de poder que se aproveitam do caos generalizado característico de sociedades distópicas.

Em Blade Runner, por exemplo, a cidade de Los Angeles no ano de 2019 é transformada em uma megalópole verticalizada e ecologicamente degradada, onde grandes arranha-céus que exibem peças de publicidade com motivos asiáticos variados se afirmam como manifestações de concreto e aço do status político da elite endinheirada. Por sua vez, esta elite tenta, a todo custo, evitar o contato com o caldeirão multiétnico compreendido pelo conjunto de classes sociais desprivilegiadas que vivem nas partes (literalmente) baixas da cidade. Pouco da paisagem urbana da Los Angeles contemporânea pode ser reconhecida na Los Angeles de Blade Runner. Por outro lado, a versão ficcional da cidade de Londres retratada em $V$ de Vingança é praticamente a mesma que a Londres dos dias de hoje. O que se dá nesse caso é uma ressignificação do uso de determinados elementos característicos da cidade. Seus edifícios popularmente identificados como "cartões-postais" - o Big Ben, o Palácio de Westminster, o Old Bailey, etc. passam a ter um valor simbólico que condiz com a ideologia fascista do partido governante, comandado pelo Alto Chanceler Adam Sutler. De forma semelhante ao descrito no romance 1984 (1949), escrito por George Orwell (1903-1950), a sociedade britânica de $V$ de Vingança é regida por um sistema político unipartidário e totalitário, no qual o direito de ir e vir das pessoas é constantemente cerceado por aparatos diversos de vigilância, monitoramento e policiamento distribuídos pelas ruas das cidades.

Essa última estratégia de fabulação distópica - que mantém aspectos facilmente identificáveis do tempo presente na realidade imaginada - é reconhecida também nos dois estudos de caso do campo das artes visuais abordados a seguir. 


\section{DA AFRODISTOPIA AO AFROFUTURISMO}

\section{William Kentridge}

William Kentridge é, provavelmente, um dos nomes internacionais vivos mais reconhecidos das artes visuais contemporâneas pela crítica e pelo público. Nascido em Joanesburgo, África do Sul, é filho do renomado sir Sydney Kentridge (1922 - ) advogado que defendeu figuras importantes na luta contra o Apartheid, tais como Nelson Mandela (1918-2013) e a família de Steve Biko (1946-1977). Portanto, mesmo pertencendo a uma minoria privilegiada branca, Kentridge teve, desde muito jovem, consciência das desigualdades sociais impostas à maioria sul-africana negra pelo sistema de segregação racial institucionalizado. Grande parte de seus trabalhos artísticos assume o Apartheid como tema, mesmo que de maneira indireta, ao representar processos de apropriação irrestrita de territórios pelos ricos de sua cidadenatal e de seus arredores numa perspectiva fabulatória. Ruas, prédios, casas, fábricas e terrenos de Joanesburgo são retratados tal como eram na época da realização desses trabalhos, mas Kentridge os imagina como espaços de enfrentamento entre personagens que, embora fictícios, não deixam de se referir a aspectos muito verdadeiros da sociedade sul-africana profundamente cindida pelo Apartheid.

Tais personagens são também alter egos do próprio artista. A Soho Eckstein ${ }^{4}$, por exemplo, Kentridge outorga o papel de um capitão da indústria ambicioso que representa os interesses da minoria branca com a qual não queria mais se associar. Por sua vez, Felix Teitlebaum, rival de Eckstein, é a contraparte amável, sensível aos acontecimentos do mundo - aquela com a qual Kentridge mais se identifica, certamente, porque é representada com as mesmas feições do artista desde seus primeiros curtas-metragens em animação.

\footnotetext{
4 É interessante analisar por um instante as escolhas de Kentridge para os sobrenomes de seus personagens, levando em conta o uso corrente do africâner - idioma de origem germânica falado por parte da minoria branca em países como a África do Sul e a Namíbia. "Eckstein", em alemão, significa "pedra angular" - ou seja, a pedra posicionada de maneira a sustentar todo um arco de pedra sobre uma dada passagem. Há aí uma alusão à ideia de que Soho Eckstein é, para a elite branca sul-africana, a figura arquetípica do homem de negócios ideal, sustentáculo do ideário de progresso então dominante.
} 
Essas obras em específico, que o próprio artista interpreta como sendo formas de "cinema da Idade da Pedra" (KENTRIDGE, 1998, p. 61), são as que melhor exemplificam as estratégias de fabulação de Joanesburgo empregadas por Kentridge para falar de questões humanas maiores a partir de aspectos micropolíticos próprios da realidade local. A técnica de animação empregada por Kentridge nesses filmes difere da metodologia tradicional, em que diferentes desenhos são feitos em folhas de papel separadas. Para se obter uma animação mais fluída, de movimentos tidos como realistas, é necessário fazer 24 desenhos para cada segundo de filme. Contudo, Kentridge alterna sucessivos apagamentos e desenhos feitos a carvão e pastel seco sobre uma mesma folha de papel de grandes dimensões. Só se troca a referida folha quando há uma mudança de cena ou de plano de câmera em vista, o que leva o espectador a perceber claramente os resquícios do desenho apagado no desenho que se sobrepõe a ele. Esses "rastros" evidenciam a materialidade do suporte e das ferramentas de desenho utilizadas pelo artista, mas também simbolizam as sucessivas modificações da paisagem urbana de Joanesburgo, na medida em que o ideal nacional de progresso da minoria branca suscitava um processo de intensa industrialização e de consequente desigualdade econômica, levando à expulsão da maioria negra dos bairros próximos ao centro da cidade e à formação do Soweto.

Isso pode ser bem visto no curta-metragem de 1989 apropriadamente intitulado Johannesburg. Nele, Kentridge apresenta os personagens Soho Eckstein e Felix Teitlebaum pela primeira vez em seu conjunto de obras. Eckstein, movido pelo desejo de tornar Joanesburgo a "segunda maior cidade do mundo depois de Paris" compra metade do território da cidade para ocupar com seus próprios negócios. Porém, enquanto Eckstein é absorvido pela burocracia que envolve administrar tantas posses simultaneamente, Teitlebaum inicia um caso amoroso com a esposa do capitalista. A ironia é que Eckstein, cada vez mais dominado pelo desejo de ter coisas, perde justamente o amor da pessoa que lhe era mais íntima. Sua esposa prefere a alternativa abnegada representada por Teitlebaum - que anda completamente nu

\footnotetext{
${ }^{5}$ Como atesta o subtítulo irônico dado à obra em questão em algumas das exposições das quais fez parte, derivado de um de seus intertítulos: Johannesburg: Second Greatest City After Paris. Vide Tone (2012).
} 
por Joanesburgo, desprovido de posses materiais, mas bastante atento às tristes cenas que vê, com operários pobres e mutilados rondando a cidade em busca de comida ou de emprego junto a Eckstein.

Há um certo momento do curta-metragem em questão, inclusive, em que Teitlebaum passa ao lado de um armário com cabeças decepadas de pessoas negras preenchendo suas prateleiras. O mutilamento físico representado aí alude não só a circunstâncias reais, mas também ao mutilamento político da população negra sul-africana, relegada à condição de cidadãos de segunda classe em seu próprio país de origem.

Apesar de todos esses acontecimentos trágicos, Eckstein permanece indiferente. Ele nem parece notar que a esposa o deixou. Tanto que, no curta-metragem Mine ${ }^{6}$ (1991), trabalhadores negros são explorados ao extremo por Eckstein, que se mantém impassível, isento de qualquer empatia e cegamente motivado pelo desejo de lucrar cada vez mais. Enquanto os trabalhadores repousam em dormitórios coletivos superlotados e tomam banho gelado, Eckstein recebe seu café-da-manhã na cama. A cafeteira de prensa francesa de Eckstein se torna o elevador que leva os mineiros às profundezas da terra para trabalhar. Só que, ao chegarem lá, as ranhuras da mina escavadas na rocha assumem os contornos de um navio negreiro visto de cima.

É somente no curta-metragem seguinte, Sobriety, Obesity and Growing Old (1991), que Eckstein sente a falta da esposa. Ele clama pelo retorno dela - e é correspondido, porque Teitlebaum aparece solitário ao final do filme, cercado por megafones que simbolizam sua sensibilidade para com os eventos trágicos que 0 circundam. Ademais, parece que Teitlebaum sofre algum tipo de perseguição da parte de Eckstein posteriormente, porque, no filme que dá continuidade à história desses personagens - Felix in Exile (1994) -, ele aparece tal como o indicado no título da obra: exilado, sozinho em um quarto, como se estivesse se escondendo de alguém. Através de um espelho - que é ao mesmo tempo janela - instalado nesse quarto, Teitlebaum observa cenas de pessoas negras sendo assassinadas nas ruas. As

\footnotetext{
6 Vale destacar aqui um jogo de palavras em inglês entre "mine" como substantivo (que significa "mina", ou seja, local de extração de algum minério) e "mine" como pronome possessivo ("meu").
} 
silhuetas de seus corpos sem vida são marcadas no chão sujo, mas logo são cobertas por folhas de jornal que as fazem desaparecer, dispersas pelo vento que sopra.

Nesse sentido, vale lembrar que, em 1994, ano de realização de Felix in Exile, ocorreram também as primeiras eleições gerais pós-Apartheid na África do Sul. Nelson Mandela foi democraticamente eleito como o primeiro presidente negro do país. Porém, ainda pesavam na memória coletiva os acobertamentos promovidos pela mídia controlada pela elite branca de inúmeros assassinatos de pessoas negras no país. Kentridge soube representar bem esse sentimento em Felix in Exile - quase na qualidade de um alerta para que não se deixe esquecer a distopia, o "mau lugar" do Apartheid na história recente da África, e as lutas de superação de relações colonialistas que até hoje deixam suas profundas mazelas no continente.

\section{Adirley Queirós e Cláudio Irineu Shokito}

Se a afrodistopia pautada pela necropolítica do Apartheid serviu de combustível para os comentários sociais incendiários próprios dos desenhos de Kentridge, uma nova qualidade de afrofuturismo surgiu nos desenhos feitos a lápis por Cláudio Irineu Shokito, um dos entrevistados-personagens do filme brasileiro de docuficção ${ }^{7}$ Branco Sai, Preto Fica (2014), dirigido por Adirley Queirós.

Shokito faz o papel de Sartana, um personagem que serve de plataforma afetiva para ele interpretar quase que a si mesmo na narrativa proposta por Queirós predominantemente ficcional, mas que tem como ponto de partida um acontecimento verídico: uma batida policial ocorrida em um baile black dos anos 1980 na região administrativa da Ceilândia, no Distrito Federal (DF). Nesse baile, tanto Shokito quanto o outro protagonista do filme, o DJ Marquim do Tropa, são baleados pela polícia. As consequências do ocorrido foram gravíssimas: Shokito precisou ter sua perna esquerda amputada do joelho para baixo, enquanto Marquim ficou paraplégico. No decorrer do

\footnotetext{
${ }^{7}$ Trata-se de um neologismo originalmente proposto por Jean-Pierre Candeloro (2000) que objetiva reconhecer a existência de uma produção cinematográfica de documentários que incorpora variados elementos fabulatórios ou poéticos em sua estrutura argumentativa, impossibilitando definir se tais filmes são ficções ou documentários segundo categorizações tradicionais stricto sensu.
} 
filme, os dois juntam forças para atacar o Plano Piloto - a parcela de Brasília $^{8}$ mais abastada por excelência, que impõe à Ceilândia e a outras regiões administrativas do DF a condição desprivilegiada de periferias - com uma espécie de bomba de cultura popular alimentada por músicas compostas e interpretadas por artistas locais.

As cenas de destruição dos elementos arquitetônicos mais conhecidos de Brasília como é o caso do Palácio do Congresso Nacional - não se dão em live-action, mas são retratadas por meio de desenhos a lápis feitos por Shokito. Diferentemente dos trabalhos de William Kentridge mencionados anteriormente, esses são desenhos estáticos. As limitações orçamentárias do filme certamente tiveram peso em tal decisão criativa, mas o potencial fabulador dos desenhos de Shokito fala mais alto. São imagens impactantes que se sucedem e que constituem em conjunto uma afirmação da vontade de existir e resistir da parte da periferia, de pensar para si um futuro diferente daquilo que planeja a Brasília da gente rica, cuja boa parte de seus residentes fixos e de ocasião (políticos) desconhece as dificuldades de ordens diversas pelas quais moradores da Ceilândia passam cotidianamente.

Em um país como o Brasil, no qual se insiste em negar a existência do racismo estrutural, tais formas de autoafirmação são mais que necessárias. Deseja-se, acima de tudo, que a História pare de repetir a si mesma no que diz respeito a estratégias de violência sistemática voltadas contra a população negra, legadas por dívidas sociais decorrentes de um passado escravocrata e colonial raramente debatido.

\footnotetext{
${ }^{8}$ Desde sua fundação, houve sucessivas leis que modificaram o nome do Plano Piloto para Brasília, e vice-versa. A mais recente (Lei no 1648, de 16 de setembro de 1997), visando reconhecer que o Distrito Federal não possui municípios, e sim múltiplas regiões administrativas que constituem a capital federal do Brasil como um todo, volta a denominar a Região Administrativa I - Brasília - como Plano Piloto. Perante esse confuso histórico legal, no âmbito de escrita deste ensaio, prefere-se recorrer ao que mais se admite popularmente - que "Brasília" é o Plano Piloto, e que as chamadas cidades-satélites (outras regiões administrativas do DF tais como a Ceilândia) não são vistas, nem admitidas como sendo parte de Brasília por razões de cunho sociopolítico autoevidentes. O próprio Adirley Queirós problematiza a questão em seu filme de 2011, A Cidade é Uma Só?, no qual relata a história de moradores de comunidades carentes surgidas nas cercanias do Plano Piloto que, na década de 1970, foram obrigados a sair de lá pela Campanha de Erradicação de Invasões (CEI) presidida pela esposa do governador do DF de então, Vera de Almeida Silveira. Muitas dessas pessoas foram alocadas numa região localizada a cerca de 30 quilômetros da Brasília projetada por Lúcio Costa. O nome dado a essa região, Ceilândia - a "terra da CEI" - deriva justamente desse fato.
} 
Negros e negras que pensam para si futuros alternativos nos quais o racismo, o colonialismo e outras formas abrangentes de preconceito deixam de existir são aqueles que criam obras chamadas de afrofuturistas nas mais variadas linguagens possíveis. No caso de Branco Sai, Preto Fica, o que se vê é um tipo de afrofuturismo que escapa das categorizações hegemônicas fáceis importadas dos Estados Unidos. Aqui não se bebe necessariamente da mesma fonte criativa que beberam artistas norte-americanos tais como os músicos Sun Ra (1914-1993) ou George Clinton (1941 - ), já que a ficção científica de alinhamento high-tech e as viagens interplanetárias ficam em segundo plano. No filme de Queirós, as tecnologias às quais a população da Ceilândia tem acesso são as mesmas de sempre - as assim chamadas "baixas" tecnologias, ou, ainda, as tecnologias "ultrapassadas", antiquadas, de baixo valor comercial, ou aquelas que podem ser articuladas/combinadas/ressignificadas por meio do improviso técnico criativo. Há sim viajantes do tempo, como é o caso do personagem Dimas Cravalanças, mas sua nave se assemelha mais a um contêiner de carga do que um veículo de design mais arrojado, tal qual as máquinas do tempo exaustivamente apresentadas em narrativas do cinema hollywoodiano. Por sua vez, Brasília (Plano Piloto) é apresentada por Queirós como uma localidade que se utiliza dos sistemas de vigilância e monitoramento mais tecnologicamente avançados. Tanto que, para serem autorizados a entrar na região, mesmo que por um curto intervalo de tempo, os moradores da Ceilândia e de outras periferias do DF precisam adquirir (ou falsificar) passaportes de alta complexidade técnica, e mostrá-los às autoridades sempre que passarem por algum ponto de controle.

Contudo, essa diferença de relacionamentos para com tecnologias distintas não constitui uma desvantagem para os moradores da Ceilândia. De maneira alguma. Marquim e Sartana são agentes instauradores não só de uma revolução política, mas de uma afirmação identitária que se dá nos termos ditados pela própria periferia. Rompendo com as formas culturais hegemônicas, os moradores da Ceilândia em Branco Sai, Preto Fica se organizam a partir da iniciativa dos protagonistas para conceber um futuro melhor para si, mesmo que seja somente pelo viés da fabulação (por enquanto). 
Sabe-se que a luta é constante nessa frente. E se envolver de maneira criativa, corajosa e engajada nessa luta, que envolve o perigo de viver sendo negro no Brasil, é algo subentendido no que afirma a última frase que aparece em Branco Sai, Preto Fica, logo após os créditos finais terem passado: "Da nossa memória fabulamos nóis mesmos [sic]" (QUEIRÓs [dir.], 2014).

\section{SOBRE O PROJETO CONTRAVOZES}

A cidade de Campinas, SP, possui espaços públicos que evidenciam a herança escravocrata brasileira problematizada no filme de Adirley Queirós. É o caso do Largo de Santa Cruz - antigamente conhecido como "Campo da Forca", porque foi lá que, segundo Pessoa (2004, p. 55), em dezembro de 1834, um escravizado com o nome Elesbão foi enforcado e esquartejado, acusado de assassinar o capitão Luiz José de Oliveira. O corpo esquartejado de Elesbão foi exibido publicamente por meses, pois as autoridades tinham a intenção de reafirmar seu poderio e mostrar para a população local qual seria a punição para escravizados que viessem a desobedecer a seus "senhores".

Atualmente, o Largo de Santa Cruz localiza-se no coração de um bairro nobre da cidade - o bairro do Cambuí. Em outros tempos, quando ainda era conhecida como Cambuisal, a referida vizinhança era espaço de realização de diversas festividades relacionadas à cultura e religiões de matriz africana (PESSOA, 2004). Contudo, com o processo de adensamento da urbanização e de verticalização da malha residencial de localidades próximas ao centro de Campinas, irmandades religiosas que administravam paróquias anexas ao Largo de Santa Cruz e ao Largo de São Benedito negavam a participação de pessoas negras em paralelo ao processo de gentrificação em curso. Moradores associados a classes política e/ou economicamente empoderadas, majoritariamente brancas, consideravam a presença de pessoas negras como algo relacionado ao histórico de "má fama" desses lugares. Logo, pressionaram autoridades no sentido de expulsar pessoas negras de lá - o que levou, por consequência, à progressiva e recorrente exclusão desses cidadãos desprivilegiados das possibilidades de vivência plena da infraestrutura urbana campineira. Isso culminou, por sua vez, no crescimento dos bairros periféricos da 
cidade e na gestação de uma cultura do medo pautada por métodos de proteção do patrimônio privado e de securatização voltados contra a diversidade.

Todas essas questões, somadas às influências exercidas pelos desenhos de William Kentridge e Cláudio Irineu Shokito, serviram de estopim para a realização de estudos de storyboard para a sequência animada de abertura de um curta-metragem de ficção em desenvolvimento, dirigido pelo autor deste ensaio. Intitulado Contravozes, o referido projeto foi contemplado com o Prêmio Estímulo à Realização de CurtasMetragens de 2019, via Programa de Ação Cultural (ProAC) da Secretaria de Cultura e Economia Criativa do Estado de São Paulo. O enredo se constitui em torno de uma ativista hacker negra chamada Lui, que objetiva conscientizar as pessoas acerca da consolidação de um projeto de poder totalitário em expansão que visa implementar um modelo de cidade inteligente (smart city) fortemente pautado pela vigilância irrestrita e ubíqua de seus cidadãos. Os únicos beneficiados por isso são os grandes conglomerados multinacionais de tecnologia da informação.

Os desenhos feitos pelo autor deste ensaio em suporte digital, utilizando o software de código aberto $\mathrm{Krita}^{9}$, buscam emular croquis feitos em um caderno de artista tradicional (sketchbook) de papel pardo, representando o olhar atento da personagem Lui sobre o que é a Campinas distópica retratada em Contravozes na chave da fabulação. Em outras palavras, trata-se de um gênero virtual de deambulação exercido pela referida personagem que visa compreender: o que é aquele mundo em que se insere; qual é a responsabilidade de cada um nos processos de transformação social que visam abolir seus "maus lugares"; e que mapeamentos podem ser feitos das resistências e táticas de contravenção usadas contra os aparatos de vigilância.

Para Michel de Certeau (1998), caminhar pela cidade, como Lui caminha, implica em uma apreensão inventiva do cotidiano. É uma apropriação do espaço compreendido pela urbanidade que se dá em um ato de "enunciação pedestre", o qual confere novos sentidos ao que se vê, e que permite exercer um olhar crítico sobre as

\footnotetext{
${ }^{9}$ Para mais informações, vide: <https://krita.org/en/>. Acesso em: 06 dez. 2020
} 
racionalidades que atuam na estruturação da forma urbana conforme as vontades e expectativas dos donos do poder.

Em suma, deambular é um modo de vivenciar a urbanidade que possibilita a seguinte reflexão:

[...] se, no discurso, a cidade serve de baliza ou marco totalizador e quase mítico para as estratégias socioeconômicas e políticas, a vida urbana deixa sempre mais remontar àquilo que o projeto urbanístico dela excluía. A linguagem do poder 'se urbaniza', mas a cidade se vê entregue a movimentos contraditórios que se compensam e se combinam fora do poder panóptico. (CERTEAU, 1998, p. 174)

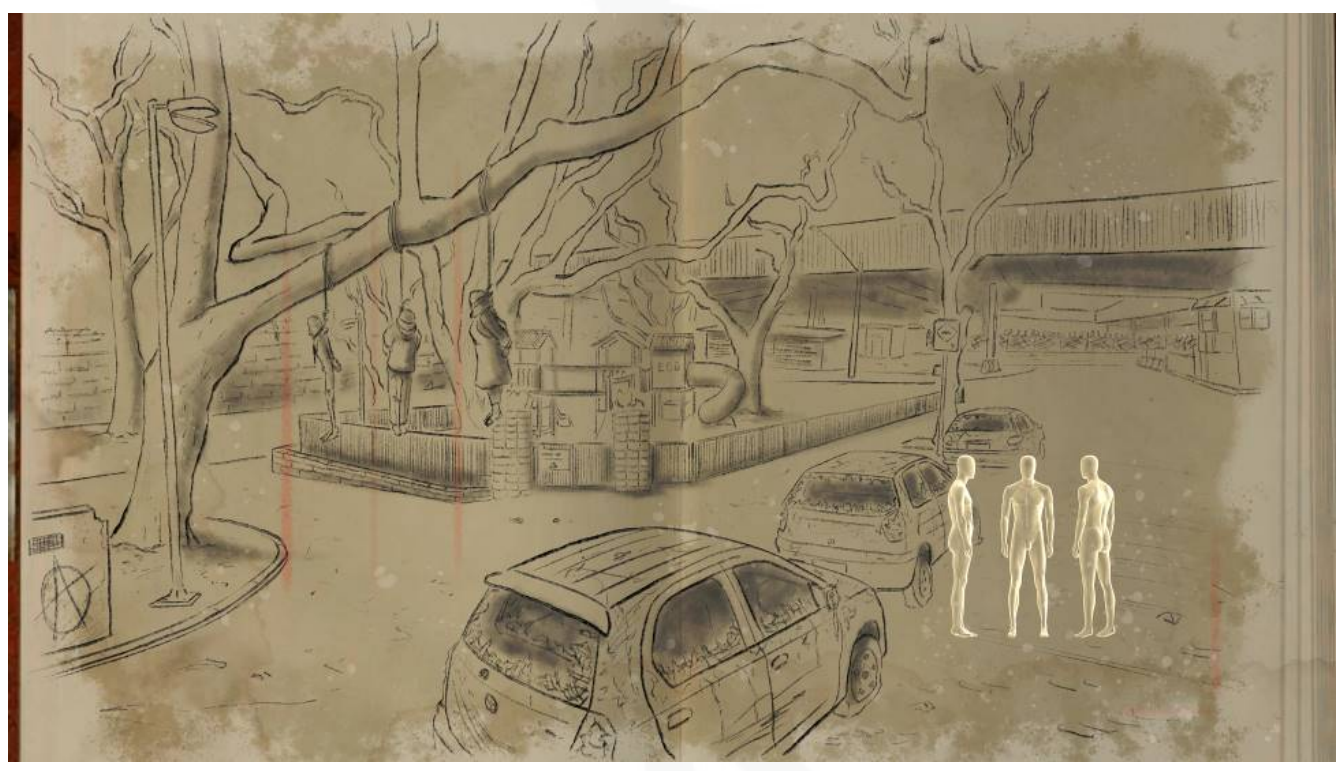

Figura 1: Estudo para sequência em animação do curta-metragem Contravozes (Largo de Santa Cruz, Campinas, SP). Fonte: Arquivo pessoal (o próprio autor).

Vale ressaltar que o planejamento da composição geral dos desenhos aqui apresentados se iniciou com um procedimento subversivo de colagem de imagens de referência extraídas do modo street view ${ }^{10}$ do aplicativo Google Maps. Representa-se determinados lugares conhecidos da cidade de Campinas com traços rápidos,

\footnotetext{
${ }^{10}$ Trata-se de um modo incorporado ao referido aplicativo/site que permite o usuário navegar virtualmente pelas ruas de qualquer cidade que tenha sido fotografada pela câmera 360 e um dos carros de propriedade da Google.
} 
característicos de rascunhos que evidenciam um pensamento em criação, e com marcações de escala que têm por base figuras humanas sem rosto, quase espectrais. Adiciona-se também novos elementos levando em conta o que tais localidades foram em tempos passados (como o já citado Largo de Santa Cruz) para imaginar seus possíveis usos no futuro - ora recuperando sua significação de outrora (pela qual o Largo de Santa Cruz volta a ser o espaço onde pessoas que lutam abertamente contra o status quo são enforcadas), ora incorporando edifícios em ruína e dispositivos de vigilância diversos nas ruas, tais como câmeras, drones, guaritas, sensores de movimento, entre outros.

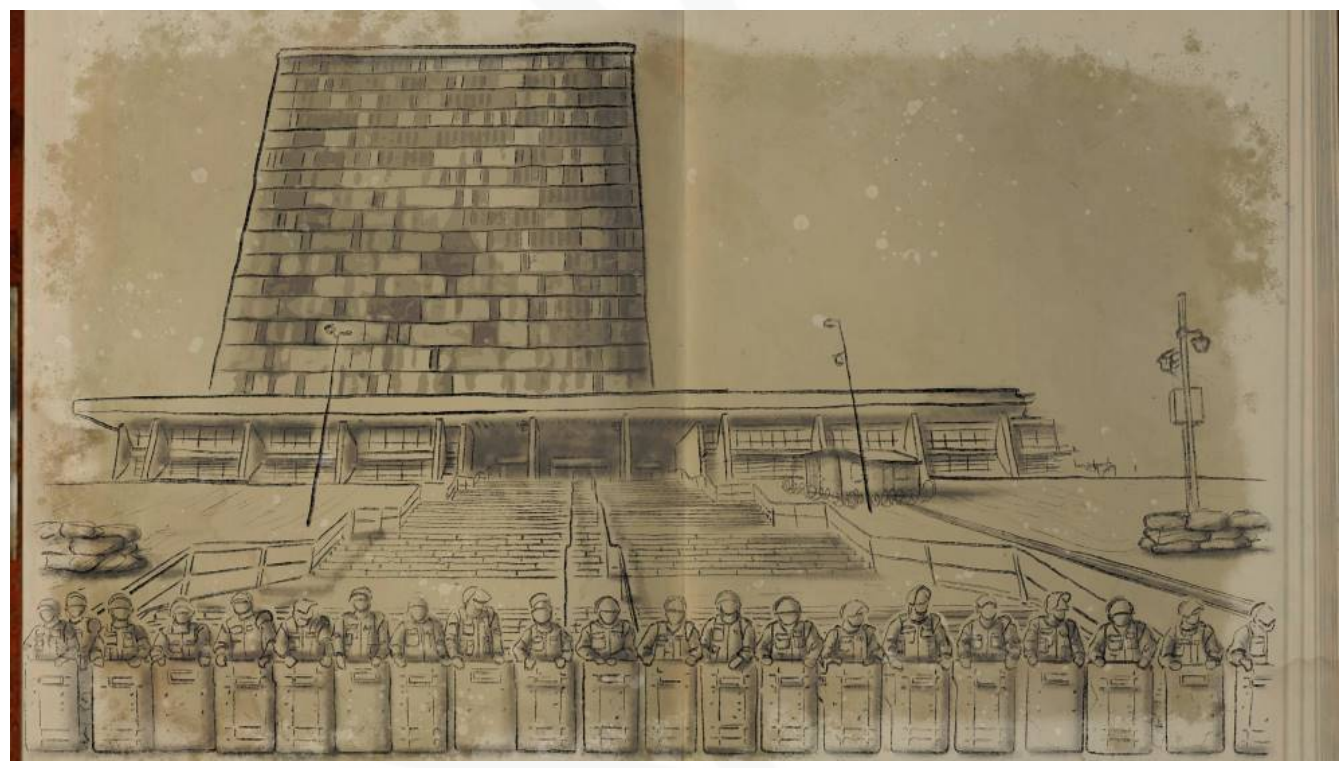

Figura 2: Estudo para sequência em animação do curta-metragem Contravozes (Palácio dos Jequitibás - sede da prefeitura municipal de (ampinas, SP). Fonte: Arquivo pessoal (o próprio autor). 


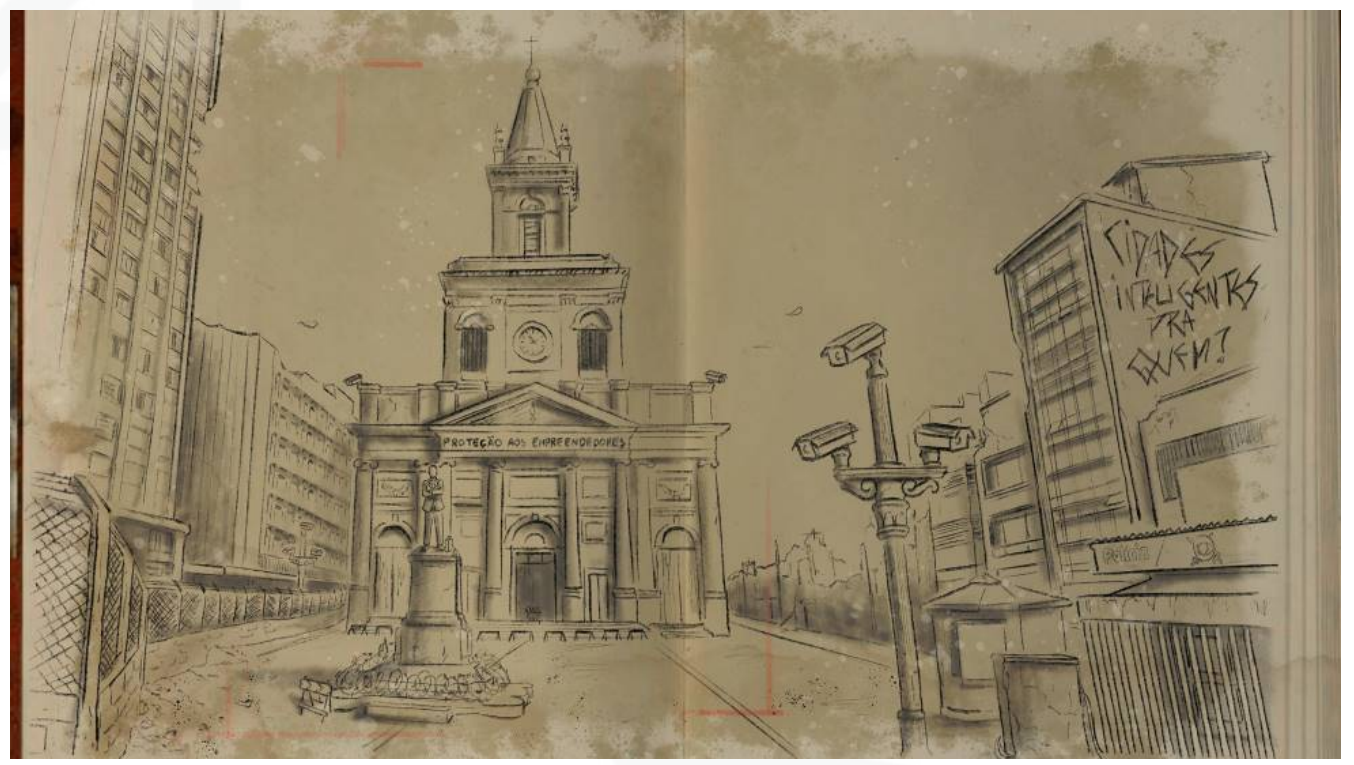

Figura 3: Estudo para sequência em animação do curta-metragem Contravozes (Catedral Metropolitana de Campinas, SP). Fonte: Arquivo pessoal (o próprio autor).

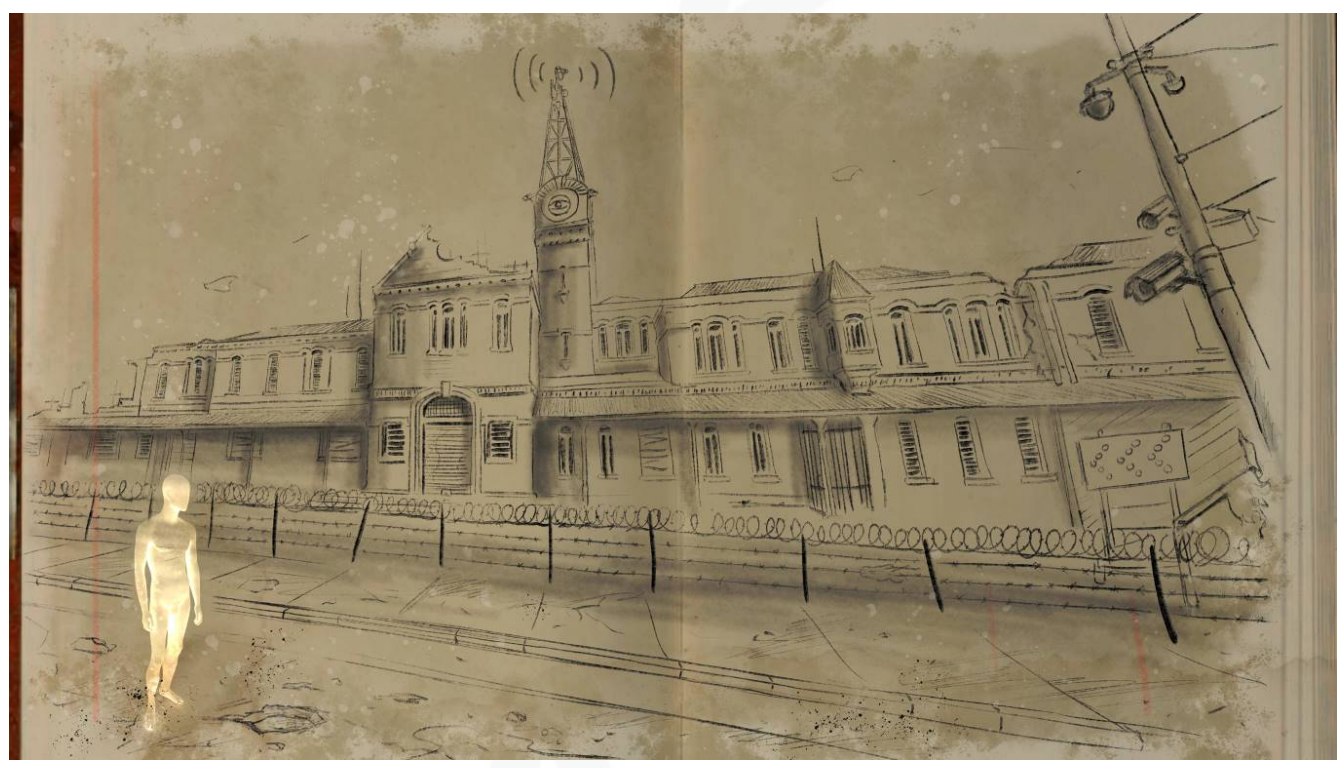

Figura 4: Estudo para sequência em animação do curta-metragem Contravozes (Estação

Cultura, Campinas, SP).

Fonte: Arquivo pessoal (o próprio autor).

Tais tecnologias de vigilância, associadas a formas de planejamento urbano excludente da Campinas dos dias de hoje que são ecoadas e intensificadas pela Campinas distópica representada nas imagens anteriores, demonstram o quanto 
artefatos materiais ou imateriais estão imbuídos não só de técnica, mas de determinações oriundas de decisões de cunho político, ideológico, cultural e econômico tomadas de antemão por elites já consolidadas historicamente. Nesse sentido, cabe destacar o que é reconhecido pelo teórico norte-americano de tecnologia Langdon Winner:

[...] máquinas, estruturas e sistemas da moderna cultura material podem ser precisamente julgados não apenas pela sua contribuição à eficiência e produtividade e pelos seus efeitos colaterais ambientais, positivos e negativos, mas também pelos modos pelos quais eles podem incorporar formas específicas de poder e autoridade. (WINNER, 1986, s.p.)

Winner (1986), inclusive, chega a comentar sobre os viadutos baixos de Long Island concebidos propositalmente desse modo para evitar que o transporte público - e, por consequência, a parcela da população que depende exclusivamente dele para se deslocar na cidade de Nova York - tivesse acesso aos parques da região. Eram os tempos da reaganomics ${ }^{11}$, e Nova York tornava-se uma metrópole que abria cada vez mais mão dos subsídios públicos para se deixar controlar por agentes empreendedores financeiros de sucesso. Ao mesmo tempo em que seu aparato público passava a ser quase que totalmente privatizado, edifícios eram construídos em celebração à nova elite econômica de então, compostas por autodeclarados selfmade men tais como o atual presidente dos Estados Unidos, Donald Trump - que, sabidamente, fez sua fortuna e fama em torno de empreendimentos imobiliários nos quais comprava terrenos ou prédios decadentes de várias cidades norte-americanas por valores irrisórios e os remodelava para serem utilizados depois como escritórios e hotéis exclusivos para os endinheirados.

Nota-se em tal retrato de época apresentado por Winner uma convergência específica entre tecnologias de produção, representadas pelo desenho arquitetônico dos referidos viadutos, e tecnologias de poder, subentendidas no exercício da especulação imobiliária e financeira em Long Island que atende aos interesses de

\footnotetext{
${ }^{11}$ Termo que identifica a política econômica neoliberal posta em prática tanto doméstica como internacionalmente pelos Estados Unidos durante o governo do presidente Ronald Reagan (1981-1989).
} 
uma classe privilegiada em detrimento daquilo que deveria balizar o conceito mais primordial de urbanismo: o de preocupação com a cidade enquanto lugar de convívio efetivamente coletivo. E isso não se restringe a Nova York - é algo que faz parte dos espaços de disputa das diferenças em praticamente todas as metrópoles da atualidade mundo afora.

Essa problemática é pouco explorada para além dos campos de discussões gerais da arquitetura e do urbanismo. Porém, através de uma análise que envolve identificar diferenças no acesso a determinadas tecnologias da cidade que refletem diferenças socioeconômicas e/ou identitárias, é possível fazer um reconhecimento da marginalidade à qual se relega indivíduos excluídos de determinados espaços de circulação, entretenimento, vivência e/ou de moradia dos centros urbanos contemporâneos. No caso brasileiro, a territorialização que impõe diversos tipos de distância entre bairros ricos e pobres - ou seja, não somente a distância geográfica, mas as que se dão também em termos sociotécnicos, de acesso a transporte público, cultura, saúde, educação, trabalho, etc. - é indicativa daquilo que afirma o escritor norte-americano de ficção científica William Gibson (2018) na epígrafe deste ensaio: enquanto as benesses utópicas dos avanços científicos e tecnológicos de hoje em dia são facilmente acessadas por classes econômica e/ou politicamente favorecidas, relega-se a distopia a classes menos favorecidas. São questões como essas que, em última instância, o projeto Contravozes visa problematizar. Seu universo distópico próprio não é nada mais que uma extrapolação das desigualdades que se autoperpetuam no Brasil do tempo presente, valendo-se da cidade de Campinas como recorte temático e fabulatório.

\section{CONSIDERAÇÕES FINAIS}

A situação de isolamento social decorrente da pandemia do novo coronavírus (Covid19) em 2020 impôs mudanças drásticas no cronograma original de produção do projeto Contravozes. Até a data de fechamento deste texto, as cenas em live-action do curta não têm data definida para serem gravadas. 
Em um cenário como esse, para o qual o filósofo Byung-Chul Han (2020) prevê o advento de uma nova etapa do capitalismo global a partir da exportação do modelo de cidades hipervigiadas asiáticas que melhor contiveram o avanço do vírus para o Ocidente, há a preocupação de que iniciativas rigorosas de controle do ir e vir permaneçam instituídas para além do tempo que perdurar a pandemia. Logo, ao contrário do que mais costuma acontecer na área do audiovisual, a realidade parece vir cada vez mais ao encontro do roteiro de Contravozes, escrito há mais de um ano. A pandemia não era então um problema, parecendo residir tão-somente como ficção explorada por enredos de filmes distópicos. Contudo, um gênero muito real de distopia, de "mau lugar", cresce na proporção em que o coronavírus se propaga e ocasiona fatalidades, com as maiores taxas recorrentemente associadas à população pobre e afrodescendente do Sul global.

Fora isso, há a problemática perene da invisibilização de narrativas outras, nãohegemônicas, que contam histórias sobre o passado da cidade que atestam a participação de pessoas negras, indígenas, LGBTQIA+'s, entre outros grupos tidos como minoritários que têm suas pautas recorrentemente desprezadas pela historiografia oficial. Para essas pessoas - que, juntas, constituem a maioria populacional numérica no país - a distopia em que muitas delas vivem cotidianamente sustenta a utopia vivida por poucos beneficiados.

Marginalizadas desde sempre, pessoas negras lutam contra processos que visam tipifica-las como indivíduos periféricos incapazes de ascenderem socialmente. Logo, sua existência é vista com menos empatia pelos olhos das elites, por mais que seja justamente o seu trabalho que possibilita a manutenção dos privilégios fruídos. A vida desses trabalhadores e trabalhadoras é menosprezada e sujeita a violências dos mais diversos tipos. Mas, felizmente, ainda há espaços de resistência contra esse gênero de necropolítica exercida com base em critérios socioeconômicos e étnicos nas cidades brasileiras contemporâneas. 
Em Campinas, pode-se citar o exemplo da Casa de Cultura Fazenda Roseira ${ }^{12}$, gerida pela Comunidade Jongo Dito Ribeiro, que se preocupa em preservar a memória negra em meio a um contexto urbano que tenta invisibilizá-la o tempo todo - ao mesmo tempo em que o referido contexto é atravessado por ruas que ostentam orgulhosamente o nome de muitos barões do café que viveram na cidade e que contaram maciçamente com trabalho escravizado negro em suas extensas lavouras.

Nos dias de hoje, a oposição se dá na forma de políticas conservadoras e de processos de especulação financeira que vêm permitindo a construção de diversos condomínios de apartamento em seus arredores nos últimos anos. Contudo, a Fazenda Roseira resiste, compartilhando as riquíssimas histórias que tem para contar com todos que a visitam e se comovem com sua existência, o que comprova toda a potência da fabulação em promover o exercício da alteridade e o compartilhamento de visões de mundo a favor de um ideal de futuro mais digno.

É essa postura de imaginar mundos possíveis de forma colaborativa e espontânea reconhecendo, mas sem temer os desafios de tempos distópicos por vir - que motiva o projeto Contravozes a continuar cada vez mais firme em seus propósitos. Refletir sobre como variados modelos de desenvolvimento urbano são socialmente excludentes de imediato, e sobre o papel da arte em denunciar e propor alternativas a essa estrutura nociva a partir de suas frestas, é só o começo dessa jornada.

\section{REFERÊNCIAS}

\section{Bibliografia citada}

BLADE Runner: O Caçador de Androides. Direção: Ridley Scott. Produção: Hampton Fancher. Estados Unidos, 1982. $117 \mathrm{~min}$, son., color., $35 \mathrm{~mm}$.

BRANCO Sai, Preto Fica. Direção: Adirley Queirós. Produção: Simone Golçalves e Adirley Queirós. Brasil, 2014. 95 min, son., color., digital.

CANDELORO, J.P. Docu-fiction: Convergence and contamination between documentary representation and fictional simulation. 2000. Dissertação

\footnotetext{
${ }^{12}$ Vide: <https://comunidadejongoditoribeiro.wordpress.com/casa-de-cultura-fazenda-roseira/>. Acesso em: 06 dez. 2020.
} 
(Mestrado em Comunicação) - Facoltà di Scienze della Comunicazione, Università della Svizzera Italiana, Lugano, Itália. Disponível em: <https://web.archive.org/web/20110911104733/http://www.bul.unisi.ch/cerc a/bul/memorie/com/pdf/9900Candeloro.pdf>. Acesso em: 22 jun. 2020.

A CIDADE é Uma Só? Direção: Adirley Queirós. Produção: André Carvalheira e Adirley Queirós. Brasil, 2011. 79 min, son., color., digital.

DE CERTEAU, M. A invenção do cotidiano: artes de fazer. 3. ed. Petrópolis, RJ. Vozes, 1998. $352 \mathrm{p}$.

DELEUZE, G. Cinema 1: a imagem-movimento. São Paulo: Brasiliense, 1985. . Cinema 2: a imagem-tempo. São Paulo: Brasiliense, 2007.

FELIX In Exile. Direção: William Kentridge. África do Sul, 1994.8 min 46 s, son., color., $16 \mathrm{~mm}$ (digitalizado).

JOHANNESBURG. Direção: William Kentridge. África do Sul, 1989. 8 min 11 s, son., color., $16 \mathrm{~mm}$ (digitalizado).

KENTRIDGE, W. 'Fortuna': Neither Programme nor Chance in the Making of Images. In: CHRISTOV-BAKARGIEV, C. (Org.) William Kentridge. Bruxelas: Societé des Exposition du Palais des Beaux-Arts, 1998.

MILL, J. S. The Collected Works of John Stuart Mill, Volume XXVIII - Public and Parliamentary Speeches Part I: November 1850 - November 1868, ed. John M. Robson and Bruce L. Kinzer (Toronto: University of Toronto Press, London: Routledge and Kegan Paul, 1988. 371 p.

MINE. Direção: William Kentridge. África do Sul, 1991.5 min 33 s, son., color., 16 mm (digitalizado).

MORE, T. Utopia. São Paulo, SP: Penguin / Companhia das Letras, 2018. 216 p.

ORWELL, G. 1984. São Paulo, SP: Companhia das Letras, 2009. 416 p.

PESSOA, A. E. S. (Org.) Conhecer Campinas numa perspectiva histórica. Campinas: Secretaria Municipal de Educação, 2004. 208 p.

SOBRIETY, Obesity and Growing Old. Direção: William Kentridge. África do Sul, 1991. $8 \mathrm{~min} 12 \mathrm{~s}$, son., color., $16 \mathrm{~mm}$ (digitalizado).

TONE, L. (Org.) William Kentridge: Fortuna. Rio de Janeiro, RJ; Porto Alegre, RS; São Paulo: Instituto Moreira Salles: Fundação Iberê Camargo: Pinacoteca do Estado de São Paulo, 2012. 315 p.

V de Vingança. Direção: James McTeigue. Produção: Lilly e Lana Wachowski. Estados Unidos, 2005. $132 \mathrm{~min}$, son., color., $35 \mathrm{~mm}$. 
ZACHARIAS, P.; ZEPPINI, P. S. Sobre aprender e fabular em educação. Linha Mestra, Campinas, n. 35, p. 278-285, mai./ago. 2018. Disponível em: <http://Im.alb.org.br/index.php/lm/article/download/56/71>. Acesso em: 05 jun. 2020.

\section{Fontes eletrônicas e sites}

COMUNIDADE Jongo Dito Ribeiro. Site oficial. Disponível em: <https://comunidadejongoditoribeiro.wordpress.com/>. Acesso em: $06 \mathrm{dez}$. 2020.

DISTRITO FEDERAL. Lei no 1648, de 16 de setembro de 1997. Diário Oficial do Distrito Federal, Brasília, 29 set. 1997. Disponível em: <http://www.sinj.df.gov.br/sinj/Norma/49606/Lei_1648_16_09_1997.html>. Acesso em: 22 jun. 2020.

FÁBULA. In: MICHAELIS Dicionário Brasileiro da Língua Portuguesa. São Paulo, SP: Melhoramentos, 2015. Disponível em: $<$ https://michaelis.uol.com.br/moderno-portugues/busca/portuguesbrasileiro/fabula>. Acesso em: 12 jun. 2020.

GIBSON, W. The Science in Science Fiction. Entrevista concedida por William Gibson e David Brin à National Public Radio. National Public Radio. Washington, DC, 22 out. 2018. Disponível em: <https://www.npr.org/2018/10/22/1067220/thescience-in-science-fiction>. Acesso em: 17 jun. 2020.

HAN, B. C. O coronavírus de hoje e o mundo de amanhã, segundo o filósofo ByungChul Han. El País Brasil. São Paulo, 22 mar. 2020. Disponível em: $<$ https://brasil.elpais.com/ideas/2020-03-22/o-coronavirus-de-hoje-e-omundo-de-amanha-segundo-o-filosofo-byung-chul-han.html>. Acesso em: 06 jun. 2020.

WINNER, L. Artefatos têm política? Tradução de Fernando Manso (NECSO/UFRJ). Reprodução livre, em Português Brasileiro, do texto original de Langdon Winner. In: . The Whale and the Reactor: a search for limits in an age of High Technology. Chicago, IL: The University of Chicago Press, 1986. p. 19-39. Disponível em: <http://www.necso.ufrj.br/Trads/Artefatos\%20tem\%20Politica.htm>. Acesso em: 14 jun. 2020. 